\title{
Economic Translation: Theoretical and Practical Issues
}

\author{
Irina Zaykova ${ }^{1, *}$ Irina Shilnikova ${ }^{2},{ }^{*}$ \\ ${ }^{1}$ Irkutsk National Research Technical University, Foreign Languages Department, 664074, Irkutsk, Russia \\ ${ }^{2}$ Irkutsk State University, International Institute of Economics and Linguistics, 664058, Irkutsk, Russia
}

\begin{abstract}
The paper deals with theoretical and practical analysis of economic translation. It is considered from two points of view: as a process and a product of rendering. As a process it is a multistage complex act of cross-cultural bilingual communication that aims to produce the closest natural equivalent to the target text. It is also characterized by a high degree of equivalence of the source text. As a product economic translation is an equivalent of the source text which is not identical due to cultural and language differences. The study reveals the interdisciplinary character of economic translation that makes it difficult to define its status. It has different nominations (economic translation, commercial translation, etc.). The analysis shows that the term "economic translation" is wider. It is due to the fact that it functions in various areas of activity (business, economy, trade and etc.). This factor affects the source texts that are different in genres and styles. The practical part of the article is devoted to the most common mistakes specified by the classification of Andreea-Rosalia Oteanu: the reading of the English text and English lexical meaning. The authors present some examples, analyze and describe them.
\end{abstract}

\section{Introduction}

The process of globalization has impacted the world since last century removing barriers and allowed access to any information all over the world [1,2]. It has also effected business activities throughout the world [1-3]. In this regard, the study of economic translation is of particular interest. Researchers in this area pay much attention to lexical aspects. In particular, a number of publications are devoted to economic terms. They explore business terminology [4], English borrowings [5], euphemisms [6]. In addition, they study metaphors in business language $[7,8]$.

Another area of research is translating different genres of economic texts (press releases, textbooks, newspaper articles, business correspondence, etc.) [9]. Studies focus on problems that translators can face: discursive aspects (framing, rhetorical figures, etc.) $[10,11]$, finding equivalents $[3,12]$.

Analysis shows that the concept of "Economic translation" is still under study. The authors try to map the field of economic translation, but in translation theory the term has not been clearly defined yet. In addition, not all its peculiarities are revealed from theoretical and practical points of view. The article aims to define the term "economic translation", identifying its common features as well as showing its specificity in practice.

\section{Economic translation as a concept}

Traditionally the term "translation" is regarded from two points of view: as a process and a product of rendering. Webster's New World dictionary gives the following definition of the term: "act, process, or instance of translating: such as a rendering from one language into another and the product of such a rendering" [13]. In other words, it can be defined as "the process of turning an original or "source" text into a text in another language" and "a translated version of a text" [14]. Let us proceed to study two definitions of the term.

Translation as a process is a complex speechlanguage activity [15]. Peter Newmark says, "A satisfactory translation is always possible, but a good translator is never satisfied with it. It can usually be improved. There is no such thing as a perfect, ideal or 'correct' translation. A translator is always trying to extend his knowledge and improve his means of expression; he is always pursuing facts and words. He works at four levels. Translation is first a science, which entails the knowledge and verification of the facts and the language that describes them - here, what is wrong, mistakes of truth, can be identified. Secondly, it is a skill, which calls for appropriate language and acceptable usage. Thirdly, an art distinguishes good from undistinguished writing and is the creative, the intuitive, sometimes the inspired level of the translation. Lastly, a matter of taste, where argument ceases, preferences are expressed, and the variety of meritorious translations is the reflection of individual differences" [16:6]. The

\footnotetext{
* Corresponding author: irazaykova@mail.ru
} 
author shows a multistage complex process in which a translator has to make significant efforts.

In addition, scholars point out that the main purpose of translation is 'to serve as a cross-cultural bilingual communication vehicle among peoples' [17]. In this context, translators "enable communication to take place between members of different culture communities. They bridge the gap between situations where differences in verbal and nonverbal behaviour, expectations, knowledge and perspectives are such that there is not enough common ground for the sender and receiver to communicate effectively by themselves" [18: 43]. Thus, translation is regarded as an act of intercultural communication in which translator works as a mediator.

Besides, it is necessary to emphasize that translation as a process aims to produce in the receptor language the closest natural equivalent to the message of the source language [19]. Consequently, it focuses on the equivalent, but it cannot be identical to the target language.

Translation as a product of rendering is the target text created to represent the source text in another language [20]. In addition, being an equivalent of the source text, as stated above, it is not identical due to differences in language and culture [21].

Considering the peculiarities of translation, it should be noted that its specificity is mostly seen in comparison with interpretation.

As analysis shows, the significant difference between translation and interpretation is the time factor. $\mathrm{R}$. Minyar-Beloruchev points out that during the process of translation there is an unlimited time, which allows to use dictionaries and various reference books, while interpretation is carried out in extreme conditions of functioning of mental interpreter mechanisms [22]. Translators first read and analyze a source language, developing a meaning hypothesis. Then they write a text in a target language, which they can check for fidelity and editorial acceptability, and change it if they find it necessary [23]. Hence, the translator always has sufficient time to think about his strategy.

In addition to the above translation unlike interpretation requires a high degree of equivalence. $\mathrm{L}$. Latyshev states, that functional and stylistic adequacy of written translation is always been expected. What is acceptable in interpretation is unacceptable in translation [24]. He is echoed by I. Alekseeva saying that the requirements of equivalence in translation are much higher, and errors are not acceptable at all [25]. Unlike translation, in oral form the denotative translation model is widely practiced [26]. According to this model, the interpreter, not caring about the form in which information is expressed in the source language, conveys the meaning of this information following the rules existing in the target language. In most cases the translator does not even think about the transfer when interpreting the individual style of the source [27]. Following the high requirements of equivalence of the target text, the translator must not only adequately transmit the source text, but also localize it, that is, adapt the text to the target group according to the content, language variant, stylistic register and degree of understanding [28]. Consequently, it can be stated that an important distinctive feature of translation from interpretation is a high degree of the target text equivalence.

Another distinctive feature is based on the fact that source texts are texts of certain complexity. They are newspaper and scientific articles, different types of documents and correspondence that are translated practically only in writing. This makes it possible to reveal another specific feature of translation. It is focused on complex texts of different functional styles and genres. Figure 1 serves to represent the peculiarities of translation as a process and a product of rendering.

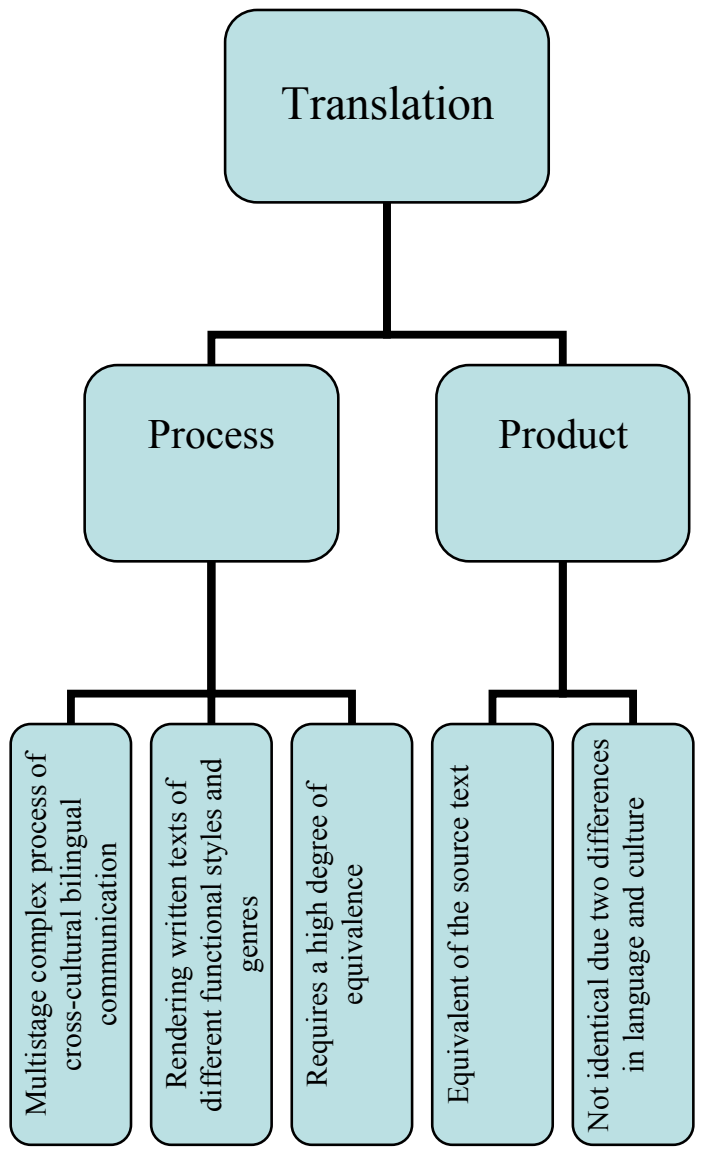

Fig.1 Translation as a process and a product of rendering

Obviously, economic translation has all characteristics inherent in translation in general. Otherwise, it would not take place as an act of crosscultural bilingual communication. As a result, economic translation is a multistage complex process of crosscultural bilingual communication the purpose of which is to produce the closest natural equivalent to the target text. It is also a process of rendering written texts of different functional styles and genres with a high degree of equivalence under sufficient time circumstances.

Besides the peculiarities inherent in translation, economic translation has its own specificity. It is an interdisciplinary area of research and professional practice [2]. In fact, economics covers various areas of activity: business, economy, trade and commerce. 
Therefore, it is difficult to define the status of the term. It is regarded as business translation, commercial translation, financial translation and economic translation. Analysis shows, business translation is more frequently used than others. This is due to the fact that translator's activity is closely connected with rendering business papers such as contracts, agreements, financial reports and invoices, as well as different types of correspondence (informative letters and advertising letters) [29]. It should be taken into account that the term "economic translation" is much wider. It implies the process of rendering texts in official business style (commercial documents and correspondence), newspaper style (newspaper articles) and scientific style (reports, articles and monographs) [29].

Summarizing the above-mentioned, it can be concluded that specificity of economic translation lays in the field of its functioning and in genre stylistic diversity of the source text (See figure 2).

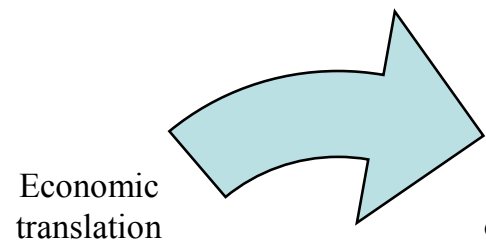

Specific field of functioning: various areas of activity

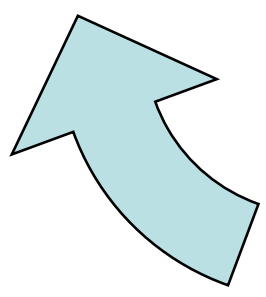

Genre stylistic diversity

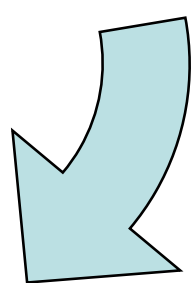

Fig. 2 Economic translation specificity

The following discussion will focus on the specificity of economic translation concerning practical issues.

\section{Definition and classification of errors in translating economic texts}

Translation errors are different from errors that would occur in spontaneous second language production, because "errors in translation mostly result from the nonequivalence between the source and the target languages" [30]. However, good translators with encyclopedic knowledge and linguistic knowledge of both the source and target languages know how to deal with them; therefore, "errors can indicate the quality of translations but in the same time they can reveal what is going on in the translator's thinking process" [31].

According to Andreea-Rosalia Oteanu the sources of errors can be classified into:
1) The reading of the English text, where the majority of mistakes in translating is done because the translators have weak reading process which influences the interpretation of original text into target language [32]. Errors found at this stage can be divided into the following categories:

a. Miscue - a term coined by Goodman [33] "referring to an incorrect guess made by a reader when reading a text. For example, the word 'program' is read as 'performance'; 'ready' as 'reading', 'county' as 'country' and so forth. Usually beginner readers make a lot of miscue errors; however, when their reading improves, they tend to make fewer of this type of errors.

b. The translator's wrong assumption of the background knowledge. "A competent translator should have an inquisitive mind constantly searching for encyclopedic knowledge" [34]. In other words, he can acquire appropriate background knowledge to interpret the source.

2) English lexical meaning. "In English lexical meaning, errors can be divided into prepositional meaning which is wrongly interpreted and expressive meanings which are translated as prepositional meaning" [30].

\section{Analyzing the mistakes in practice}

So far, two major sources of errors presented by the authoritative people induced us to analyze the mistakes which are often made by the students studying interpretation in the professional sphere "Economics" and "Trading".

While analyzing their works, we managed to classify the errors according to the most frequently occurring and thus might be viewed as specific and characterizing the difficulties in rendering from English into Russian.

The first widely made mistake is the absence of pragmatic analysis before starting rendering the text. "The factors of communicative situation in which the source text is used are of decisive importance for text analysis because they determine its communicative function. This leads to extratextual dimensions that are: intention, receiver, medium, place, time, occasion and function" [32]. The young interpreters prefer to start translating without clarifying the details of article being rendered. It leads to such mistakes as the wrong translation of the time of the event (instead of present tense they use past and vice versa), the wrong interpretation of the source of the information, for instance: the newspapers "the Daily Telegraph", "the Independent on Sunday", "The Times" are often called by magazines or websites. Another rude mistake to be dealt with here is the misunderstanding of the motive, the genre, and the subject matter. The motive in many economic articles is that these news reports have been written because something of importance has happened. The genre, which is related to the structural aspect of the text, is an informative newspaper. The subject matter is indicated in the title. For example: the title of the article "Trading Economics Across the Atlantic: Jan Tinbergen and Milton Friedman" [35] was misinterpreted as 
undertaking economic activity across (through) the Atlantic Ocean, though the article was devoted to the cooperation between the countries situated around the Atlantic Ocean.

As for the mistakes in lexical meaning, the widely spread mistakes are connected with the economic terms. The most common are the translation of the type of legal entities. These errors are often made due to the difference of the legal systems between Russia and foreign countries. For example, the abbreviation "SA" might be used only by corporations (enterprises, issuing the shares for investors) only in such countries as France, Belgium, Switzerland and some other countries of Europe, but offshore zone countries use this abbreviation to show their limited liability, and for these countries the English equivalent will be LLC. One more example "publicity traded company" ("What are Publicly Traded Companies?" [36] means the company which shares circulate freely in the stock exchange market, but not the freely transferable company.

Other problems in lexical interpretation are dealt with the idioms, set expressions and metaphors. There are several sentences from the above-mentioned article "Trading Economics across the Atlantic: Jan Tinbergen and Milton Friedman" [35] to exemplify it:

'He was set on resolving the problems of society, and for that ideal economics was to be a better vehicle than physics.' - the word 'vehicle' was translated directly as 'a means of transport' instead of 'way' or 'method', 'device'.

'It earned him, together with his more theoretically oriented colleague and friend Ragnar Frisch the first Nobel Prize in economics in 1969.' - the verb 'to earn' has the meaning 'to have / bring respect to somebody' but not 'to make money /profit'.

One more example from another source:

'Regional benchmarking is also a useful tool to inform strategic intelligence initiatives.' [37] 'intelligence' might not be interpreted as a "the ability to acquire and apply knowledge and skills' but as 'a process of reconnoitering'. The word 'benchmarking' vice versa is translated with the help of tracing and there is no necessity to find out the proper Russian variant.

What raise difficulties are phrasal verbs and idioms that have to be translated according to the context. In the article "Will Europe's unemployed pay the price of a single currency?" by Tony Barber [38] there is an idiom 'get off the ground' which is translated as a 'introduce moneda euro'("If they fail to do so, it is quite conceivable that the Euro will not get off the ground"). The verbs 'to squeeze' and 'to prune' may constitute a problem for the translator because here 'squeeze' means 'a restrange' and 'prune' - 'reduce'('But the EU member-state (except, it seems, Britain again) is happy at the prospect of being left out in 1999, and so most governments have embarked on the unpopular course of squeezing public spending and pruning their welfare systems').

To sum up, the problems that a translator may face dealing with economic texts are: a difficulty in understanding the concepts and vocabulary due to the long and complex sentences. The course of these mistakes mostly lies in the personal qualities and intelligence of the interpreter, and the fact that there is no possibility of interpretation, requiring general knowledge of the economic field.

\section{Conclusion}

The paper has attempted to analyze economic translation as a concept and to reveal its peculiarities in practice. Theoretical analysis shows that on the one hand it is a multistage complex process of cross-cultural bilingual communication. On the other hand, it is a product of the source text rendering into another language wherein the target text cannot be identical. However, the aim of this translation is to produce the closest natural equivalent to the target text. In addition, economic translation is characterized by interdisciplinary character that causes the nominative component and the diversity of styles and genres of the source texts. It is also different in its multifunctionality due to various areas which economics cover. All these factors directly affect the texts that translators have to face in their practice.

The majority of mistakes which arise during the students' translation work on economic texts are generally connected with the lack of desire to clarify the details of the article being rendered, a difficulty in understanding the concepts and vocabulary, mostly due to the long and complex sentences. Modern gadgets and availability of the Internet access simultaneously simplify the translation process, and at the same time decrease the level of background knowledge which is a sufficient part of a success. The only way out of this problem might be the decrease of background knowledge. The important role here belongs to the teacher who might develop and constantly sustain the students' interest.

\section{References}

1. M. Cronin, Translation and globalization (Routledge, London, 2003)

2. Ł. Biel, V. Sosoni, Perspectives Studies in Translation Theory and Practice 25, 351-361 (2017)

3. M.V. Melnichuk, V.M. Osipova, IEJMEMathematics 11 (7), 2503-2514 (2016)

4. P. Kelandrias, The translation of economic texts (Diavlos, Athens, 2007)

5. R. Stolze, Across Languages and Cultures 4 (2), 187-203 (2003)

6. C. Resche, Journal des Traducteurs 44 (4), $617-$ 632 (1999)

7. S. Kermas, Studies in specialized discourse, 109130 (2006)

8. P.A. Fuertes Olivera, S. Nielsen, Terminology. The Dynamics of Terms in Specialized Communication: an Interdisciplinary Perspective 17(1), 157-180 (2011) 
9. H. Buzelin, M. Dufault, C. Foglia, The Translator 21(1), 24-49 (2015)

10. Th. Kaniklidou, J. House, Minor Translating Major 5, 60-80 (2013)

11. K. Smith, Language and Literature 15 (2), 159-182 (2006)

12. P.V. Anderson, Technical Communication (Cengage Learning, Wadsworth, 2010)

13. Webster's New World dictionary, URL: www.merriam-webster.com

14. R. Nordquist, Translation: Definition and Examples, URL: www.thoughtco.com

15. L.L. Nelyubin, Explanatory translation dictionary (Flinta: Nauka, Moscow, 2003)

16. P. Newmark, A Textbook of Translation (Prentice Hall, London, 1988)

17. M.A. Sim, A.M. Pop, Managing Problems when translating economic texts, URL: http://anale.steconomiceuoradea.ro/volume/2012/n 2/021.pdf

18. C. Nord, Iha do Desterro 33, 41-55 (1997)

19. E.A. Nida, Readings in General Translation Theory 2, 153-162 (1988)

20. V.N. Komissarov, Modern Translation Science (ETS, Moscow, 2004)

21. L.K. Latyshev, Translation: Problems of Theory, Practice and Methods of Teaching (Prosveshceniye, Moscow, 1988)

22. R.K. Minyar-Beloruchev, Theory and Methods of Translation (Moskovskiy Litsey, Moscow 1996)

23. D. Gile, Translation Research and Interpreting Research: Traditions, Gaps and Synergies, 10-34 (2004)

24. L.K. Latyshev, Technology of Translation (Tezaurus, Moscow, 2000)
25. I.S. Alekseeva, Introduction into Theory of Translation (Academiya, Moscow, 2004)

26. V.N. Komissarov, A Word on Translation (Mezhdunarodnye otnosheniya, Moscow, 1973)

27. T.V. Voevodina, Tetradi Perevodchika 20, 66-77 (1983)

28. J. Zeumer, H. Salevsky, Die Verantwortung des Übersetzers in Europa neuer (Lang, Frankfurt am Main, 1996)

29. I.V. Zaykova, Modeling the economic macrodiscourse in teaching translation to university students (Irkutsk National Research Technical University, Irkutsk, 2017)

30. M. Baker, In other words: A Coursebook on Translation (London and New York, Routledge, 1992)

31. C. Seguinot, Interpreting Errors in Translation, URL: https://www.erudit.org/fr/revues/meta/1990v35-n1-meta327/004078ar/

32. R. Olteanu, Errors and Difficulties in Translating Economic Texts (Editura Sfântul Ierarh Nicolae, 2012)

33. K.S. Goodman, Read. Res. Quat 5, 1, 9-30 (1969)

34. B. Hatim \& I. Mason, Discourse and the Translator (London and New York, 1990)

35. J. Tinbergen, M. Friedman Trading Economics Across the Atlantic, URL: https://www.academia.edu/36197732/Trading_Eco nomics Across the Atlantic Jan Tinbergen and Milton Friedman

36. Accounting Course, URL: www.myaccountingcourse.comSm

37. Smart Specialization Platform, URL: http://s3platform.jrc.ec.europa.eu

38. T. Barber, Indep. URL: https://www.independent.co.uk 